\title{
CORYNOSOMA CETACEUM IN THE STOMACH OF FRANCISCANAS, PONTOPORIA BLAINVILLEI (CETACEA): AN EXCEPTIONAL CASE OF HABITAT SELECTION BY AN ACANTHOCEPHALAN
}

\author{
F. J. Aznar, A. O. Bush ${ }^{\star}$, J. A. Balbuena, and J. A. Raga \\ Departamento de Biología Animal and Instituto Cavanilles de Biodiversidad y Biología Evolutiva, Universitat de València, Dr. Moliner 50, \\ 46100 Burjasot, Valencia, Spain
}

\begin{abstract}
Adult acanthocephalans are typically found in the intestine of vertebrates, where they can readily absorb nutrients. However, Corynosoma cetaceum has been frequently reported in the stomach of cetaceans from the Southern Hemisphere. The ecological significance of this habitat was investigated by examining data on number, sex ratio, maturity status, biomass, and fecundity of C. cetaceum in different parts of the digestive tract of 44 franciscanas Pontoporia blainvillei. Individual C. cetaceum occurred in the pyloric stomach (PS) and, to lesser degrees, in the duodenal ampulla (DA) and the main stomach (MS). Females outnumbered males in all chambers, although the sex ratio was closer to 1:1 in the MS; there also was a higher proportion of nongravid females, with a smaller biomass in the MS than in the PS and the DA. This evidence suggests that cystacanths are released from prey tissues in the MS, where entire prey are reduced to semi-fluid chyme. The 3 chambers harbored gravid females that did not differ significantly in mean biomass or fecundity. The maturity status of females was nearly identical between the PS and the DA. In the MS, the higher proportion of non-gravid females is probably due to the occurrence of newly recruited females to this site. Mean biomass and fecundity of gravid females covaried strongly and positively among chambers within hosts. These results suggest that there are no major differences between the 3 chambers with respect to the suitability for reproduction by $C$. cetaceum. However, although the MS is the largest chamber, it harbored the smallest number of gravid females. Interestingly, worms were largely restricted to the aboral portion of the MS, a sheltered region where a concentration of chyme, and thus nutrient availability, likely occurs. Linear distribution differences of gravid female C. cetaceum at increasing intensities suggest that reproductive females occupy chambers according to available space. In summary, the stomach should be considered the main habitat for C. cetaceum. The choice of this habitat is puzzling because other Corynosoma species occur in the intestine, and because the stomach of cetaceans is not an absorptive site.
\end{abstract}

Adult acanthocephalans inhabit the digestive tracts of vertebrates (Crompton, 1973). The preferred site for most species is the intestine (especially the middle region [Petrochenko, 1956]), apparently due to their requirement for simple nutrients that can be absorbed across the body wall (Crompton, 1973; Starling, 1985). However, some species infecting fish have been recorded in the stomach (Petrochenko, 1956), possibly because the stomach of fish is known to be a region of nutrient absorption (Crompton, 1973). Within the groups of acanthocephalans infecting birds and mammals, only 2 species, both in the genus Corynosoma, have been reported as adults from the stomach. Corynosoma hamanni was mostly found in the duodenum of Antarctic seals, but about $3 \%$ of the component population was found in the pyloric region of the stomach (Zdzitowiecki, 1984). On the other hand, adult Corynosoma cetaceum have repeatedly been reported from the stomach and duodenum of at least 3 species of cetaceans from the Southern Hemisphere (Brownell, 1975; Kagei et al., 1976; Figueroa and Puga, 1990; Torres et al., 1992; Aznar et al., 1994; Corcuera et al., 1995; Andrade et al., 1997; Aznar et al., 1999).

The presence of adult acanthocephalans in the stomachs of marine mammals is puzzling because the digestive and absorptive functions in these hosts are well separated; the stomach is involved only in digestive functions as in other mammals (Gaskin, 1978; Berta and Sumich, 1999). This raises the question over whether Corynosoma reported from the stomach might represent recently recruited worms or worms located in an abnormal habitat (Crompton, 1973; Kennedy, 1985). Kagei et al. (1976) reported gravid C. cetaceum in the stomach of francis-

Received 24 July 2000; revised 15 November 2000; accepted 15 November 2000.

* Department of Zoology, Brandon University, Brandon, Manitoba, Canada R7A 6A9. cana dolphins Pontoporia blainvillei, suggesting that the worms were not recruited recently. Moreover, data on frequency of occurrence in several locations led Andrade et al. (1997) to suggest that the pyloric stomach should be considered the main attachment site in franciscanas. In any event, information necessary to clarify the role of the stomach as a habitat for $C$. cetaceum is lacking. In the present paper, this question is addressed using data on number of individuals, sex ratio, maturity status, biomass, and fecundity of $C$. cetaceum from different regions of the digestive tract of franciscanas. Habitat selection patterns are also considered in relation to available evidence about the host's digestive physiology.

\section{MATERIALS AND METHODS}

\section{Anatomical description of habitats}

The stomach of the franciscana consists of 3 compartments (Fig. 1). Unlike most dolphins, franciscanas lack an esophageal pouch, i.e., the so-called forestomach, and the esophagus is connected directly to the main stomach. This is the largest chamber and has the appearance of a pear-shaped, thick-walled sac where entire prey are stored and digestion begins. A narrow opening near the bottom of the main stomach leads to the connecting channel. This narrow duct follows a tortuous course (simplified in Fig. 1) that terminates at the pyloric stomach, which is a J-shaped, elongated tubular chamber ending with the pyloric sphincter. Histological observations revealed that the connecting channel can be regarded as part of the pyloric stomach (Yamasaki et al., 1974). The stomach is followed by a funnel-shaped structure, the duodenal ampulla that is separated from the intestine proper by a superficial constriction (Yamasaki et al., 1975).

\section{Data collection}

Forty-four franciscanas accidentally caught in shark fisheries off $\mathrm{Ne}$ cochea $\left(38^{\circ} 27^{\prime} \mathrm{S}, 58^{\circ} 50^{\prime} \mathrm{W}\right)$ and Claromecó $\left(38^{\circ} 52^{\prime} \mathrm{S}, 60^{\circ} 05^{\prime} \mathrm{W}\right)$ in Buenos Aires Province, Argentina, were sampled from late October to early December 1988-1990. Dolphins were removed daily from the nets and their digestive tracts removed and either examined immediately or stored in commercial freezers until examination. The entire process 


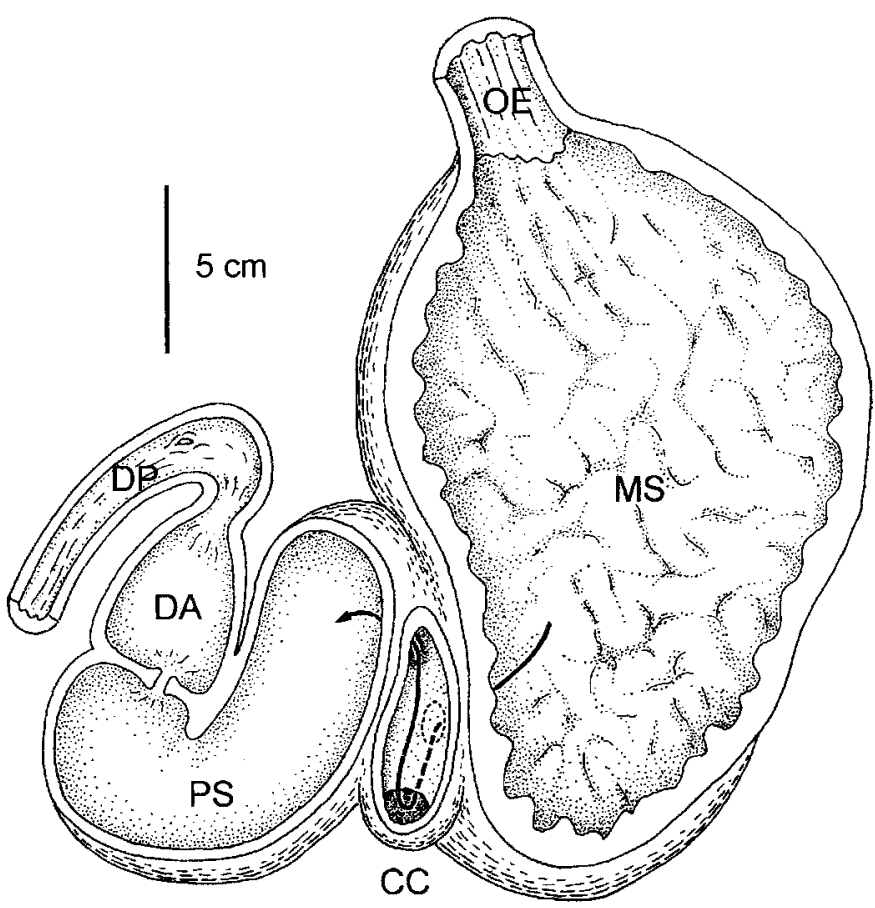

FiguRe 1. The upper digestive tract of the franciscana dolphin Pontoporia blainvillei: OE, esophagus; MS, main stomach; CC, connecting channel; PS, pyloric stomach; DA, duodenal ampulla; DP, duodenum proper. Adapted from Yamasaki et al. (1974), courtesy of Okajimas Folia Anatomica Japonica.

could take up to $24 \mathrm{hr}$ after host death. Information on the attachment of $C$. cetaceum specimens was limited to a qualitative assessment of the number of attached worms and the sites of attachment. The contents of the main stomach (hereafter referred to as MS), pyloric stomach (PS) (including those of the connecting channel), duodenal ampulla (DA), and the rest of the intestine (RI) were separately flushed through a 0.2$\mathrm{mm}$ sieve. Attached C. cetaceum were removed from the mucosa of each chamber. Parasites were washed in saline solution, preserved in $70 \%$ alcohol, and sent to the University of Valencia for examination. A few specimens of the nematode Anisakis simplex were also found in all chambers (mean abundance $\pm \mathrm{SD}, 2 \pm 2$ ) and of the digenean Hadwenius pontoporiae in the PS and the DA $(2 \pm 3)$. Given the small number of nematodes and digeneans found, it was assumed that neither species had demonstrable effects on habitat selection patterns by $C$. cetaceum at the degree of resolution we employed, i.e., among chambers.

\section{Distribution}

The distribution of C. cetaceum was described using 2 methods. First, the infection parameters were calculated for each site. For convenience, the terminology defined by Bush et al. (1997) is applied here for particular sites, i.e., prevalence in the DA, mean abundance in the PS, etc. A very small proportion of $C$. cetaceum $(<1 \%$ of the total sample) was found in the RI, where, unlike at other sites, all worms were found free in the lumen. This was interpreted to mean that these worms were senescent and were passing out from anterior locations. Therefore, these worms were excluded from subsequent analyses, except for calculations on sex ratios, where information from the RI became useful. Second, the procedure devised by Bush and Holmes (1986) was used to describe linear distribution patterns. The 0th (anterior worm), 50th (median worm), and 100th (posterior worm) centiles of worm distribution were calculated at the infrapopulation level assuming a uniform distribution of worms within each stomach chamber. A Wilcoxon test was employed to test for gender differences in median worm position.

\section{Sex ratio}

Statistical comparison of sex ratio among chambers posed 2 problems. First, Pearson chi-square and related tests $(G$, Fisher test) assume that the objects counted are independent and identically distributed (Garson and Moser, 1995). As parasites are often recruited in packets and their populations are typically aggregated, these statistics are not valid to test for sex ratio differences. Second, sex ratios per chamber, e.g., number of males/total number of worms, could be obtained at the infrapopulation level, then compared with tests for several related samples. However, this procedure can mislead because sex ratios are drawn from disparate sample sizes, ranging from 1 to several hundred worms, i.e., sex ratios are not weighted by sample size. These problems were dealt with as follows. The number of males and total number of worms in chamber $\mathrm{k}$ were summed across hosts, then the sex ratio (males/males + females) in chamber $\mathrm{k}$ was calculated. The $95 \%$ confidence interval was set for this sex ratio estimator based on 1,000 bootstrap replicates. Replicates were obtained by sampling with replacement from the 44 hosts. Confidence intervals were corrected by the bias-corrected percentile method (Efron, 1982).

\section{Maturity}

Females were used to describe maturity patterns in each chamber. Females were cleared in lactophenol and classified under a stereomicroscope as stage 1 (ovarian balls only), stage 2 (containing a mixture of ovarian balls and developing acanthors), or stage 3 (containing a mixture of ovarian balls, developing and fully developed acanthors) (see, e.g., Bates and Kennedy [1990] for a similar criterion). To obtain representative samples from each chamber, 29 hosts were chosen in which each of the 3 chambers had at least 10 females. The linear distribution of each maturity stage was described using Bush and Holmes' (1986) method as described above. Differences in linear position among developmental stages were tested with a Quade test. This test is an extension of the Wilcoxon test for multisample situations and appears to have a higher statistical power relative to the Friedman test when the number of treatments is less than 5 (Conover, 1980). Finally, Spearman correlation tests were performed to examine significant relationships between number of gravid females, i.e., stages $2+3$, and the position of the anterior, median, and posterior worm.

\section{Biomass}

Females were left overnight in refrigerated tap water and, prior to weighting, were left briefly on dry paper to remove the excess of water. Females of each developmental stage from each chamber in each host were weighed together to the nearest $0.0001 \mathrm{~g}$; therefore, there is a single weight measurement for each chamber per dolphin. Total weight was then divided by the number of females to obtain the mean weight per female. Values of mean weight per female were used to explore with Quade tests biomass differences of each developmental stage among chambers. We also used a Kendall test to examine whether mean weight of gravid females covaried significantly among chambers within hosts.

\section{Fecundity}

Fecundity was estimated as the number of acanthors per female (Bates and Kennedy, 1990). Fifteen hosts that had more than 5 females of stage 3 in each chamber were selected; then, 5 of those females from each chamber in each host were sampled. Fecundity of each specimen was estimated following the method of Bates and Kennedy (1990): each specimen was weighed and its contents were washed into a beaker and the volume made up to $10 \mathrm{ml}$, then continually agitated using a magnetic stirrer for at least $5 \mathrm{~min}$. Ten separate samples of $10 \mu \mathrm{l}$ were taken and the number of acanthors counted. The mean number of acanthors obtained from these samples was extrapolated to the total volume. In each host, values of individual fecundity were averaged per chamber; then, fecundity differences among chambers were tested for with a Quade test, and fecundity covariation among chambers within hosts was examined with a Kendall test.

\section{RESULTS}

All dolphins were infected with $C$. cetaceum (mean abundance \pm SD, $718 \pm 605$; median, 531) and 31,591 worms were 
TABLE I. Infection parameters of the acanthocephalan Corynosoma cetaceum in 4 sites from 44 franciscana dolphins Pontoporia blainvillei: main stomach (MS), pyloric stomach (PS), duodenal ampulla (DA), and remaining intestine $(\mathrm{RI})$.

\begin{tabular}{|c|c|c|c|c|}
\hline & MS & PS & $\mathrm{DA}$ & RI \\
\hline Prevalence & $36 / 44$ & $43 / 44$ & $39 / 44$ & $31 / 44$ \\
\hline \multicolumn{5}{|l|}{ Abundance } \\
\hline Mean $\pm \mathrm{SD}$ & $59 \pm 98$ & $572 \pm 467$ & $82 \pm 117$ & $6 \pm 8$ \\
\hline Median & 31 & 440 & 48.5 & 1 \\
\hline Range & $0-473$ & $51-1,595$ & $0-626$ & $0-26$ \\
\hline Mean $\% \pm \mathrm{SD}^{*}$ & $11 \pm 10$ & $78 \pm 14$ & $11 \pm 9$ & $1 \pm 2$ \\
\hline
\end{tabular}

* Percentages are calculated on an infrapopulation basis, i.e., no. of worms in chamber $\mathrm{i}$ in host $\mathrm{j} /$ total no. of worms in host $\mathrm{j}$.

collected, $87.1 \%$ from the stomach. Most specimens were found firmly attached at each site, except in the RI, where all worms were found free in the lumen. Values for infection parameters studied in each site are shown in Table I. The PS was, by far, the location harboring the greatest number of worms; the MS harbored the fewest (Table I). The position of the median worm did not differ between genders (Wilcoxon test, $Z=0.80, \mathrm{n}=$ 44, $P=0.424$ ).

The sex ratio was biased against males (overall, 0.43; mean $\pm \mathrm{SD}, 0.44 \pm 0.08$ ). However, values differed among sites (Fig. 2). In the RI, males exceeded females. In the MS, the PS, and the DA, sex ratios favored females, although the ratio was closer to 1:1 in the MS (note that its confidence interval does not overlap with the confidence interval of the sex ratio in the PS).

Values for infection parameters studied for the 3 developmental stages of female $C$. cetaceum are shown in Table II. Gravid females occurred in the PS and the DA of the 29 analyzed hosts and in the MS of 28 hosts. Proportions of developmental stages were nearly identical between the PS and the $\mathrm{DA}$; in the MS, a higher proportion of stage 1 females was found (Table II). The position of the median worm differed significantly among developmental stages (Quade test $T_{(2,56)}=$ 15.02, $P<0.001)$. A posthoc comparison indicated that the median worm of stage 1 was significantly more anterior than those of 2 and $3(P<0.05)$, whereas median worm position did not differ between stages 2 and 3 . At increasing numbers

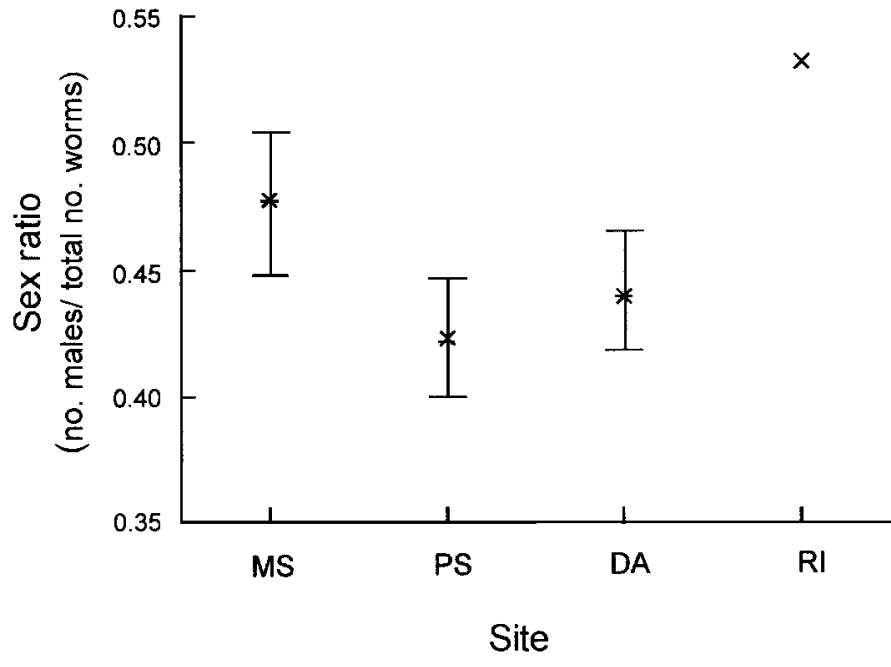

FIGURE 2. Sex ratio values of Corynosoma cetaceum from 44 franciscanas Pontoporia blainvillei in different sites of the digestive tract: main stomach (MS), pyloric stomach (PS), duodenal ampulla (DA), and remaining intestine (RI). The $\mathrm{X}$ indicates the empirical value obtained for each site using the total host sample; the bar through X corresponds to the estimated mean value for 1,000 bootstrap replicates; the segment represents the $95 \%$ confidence interval calculated by the bootstrap procedure.

of gravid females, the median worm $\left(r_{s}=0.52, \mathrm{n}=29, P=\right.$ $0.008)$ and the posterior worm $\left(r_{s}=0.80, P<0.0001\right)$ of gravid females were more posteriad, but the anterior worm did not differ in position $\left(r_{s}=-0.34, P=0.07\right)$ ( $P$ in the 3 tests corrected by the sequential Bonferroni correction [Rice, 1989]). The posteriad shift in the position of the median and posterior worm at increasing numbers of gravid females was strongly curvilinear; in infrapopulations with more than 100 gravid females, positions reached a roughly constant value, i.e., about the center of the PS for the median worm, and the end of the DA for the posterior worm (Fig. 3).

Mean biomass for each stage in each chamber are shown in Table III. Quade tests revealed no significant biomass differences among chambers for stages $2\left(T_{(2,44)}=0.23, P>>0.05\right)$ and $3\left(T_{(2,52)}=1.13, P>>0.05\right)$, but did for stage $1\left(T_{(2,48)}=\right.$ $5.42, P<0,01)$. A posthoc comparison indicated that only the

TABLE II. Infection parameters of 3 developmental stages of Corynosoma cetaceum in 3 sites from 29 franciscana dolphins Pontoporia blainvillei: main stomach (MS), pyloric stomach (PS), and duodenal ampulla (DA).

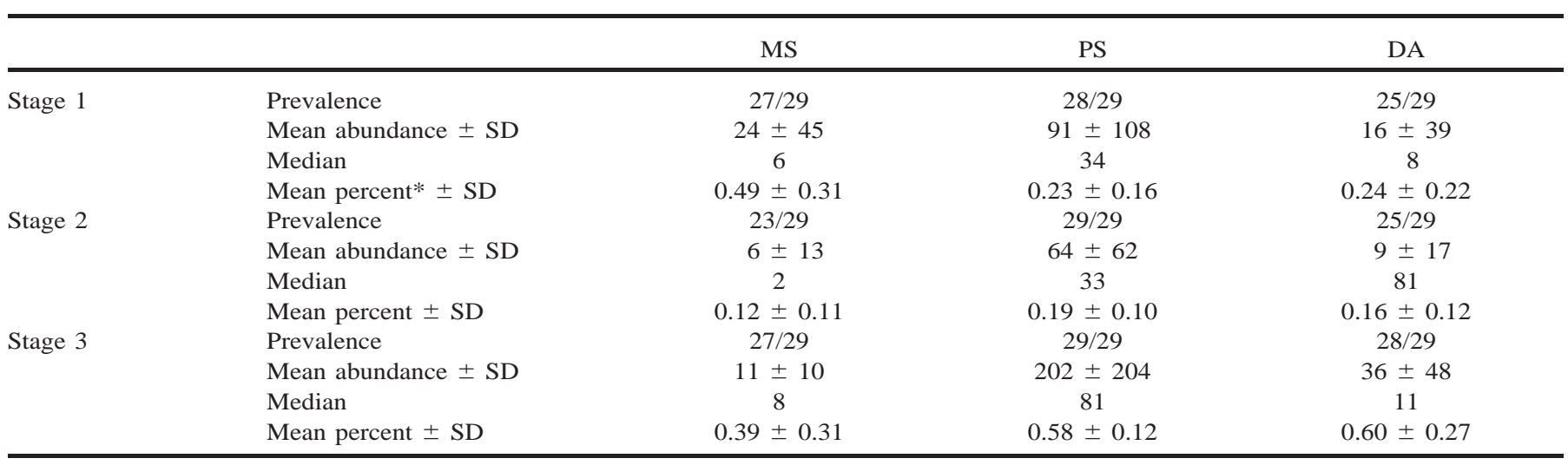

* The proportion of each stage is calculated for each site in each infrapopulation. 

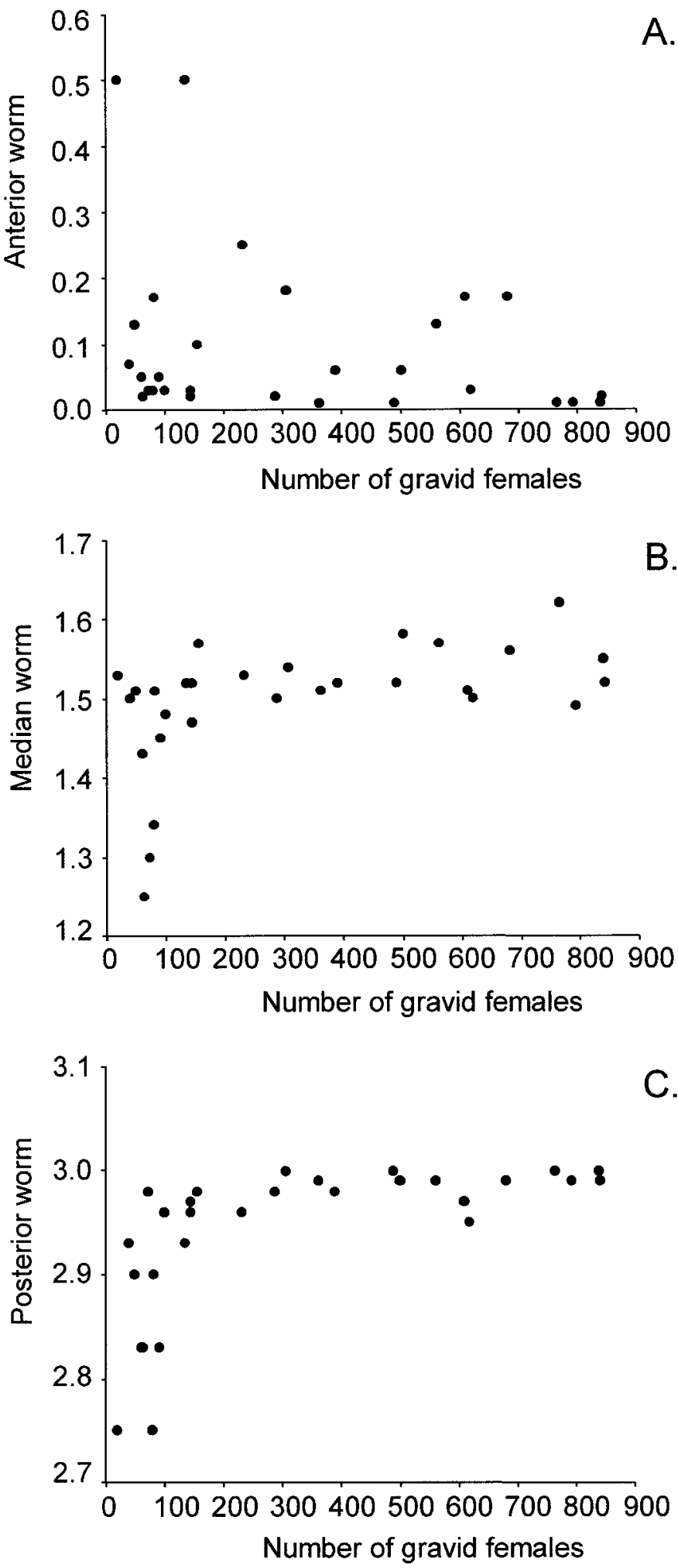

Figure 3. Position of the (A) anterior, (B) median, and (C) posterior worm for gravid female Corynosoma cetaceum in the digestive tract of franciscanas Pontoporia blainvillei at increasing number of gravid females. Position values range from 0 (the anterior end of the main stomach) to 3 (the posterior end of the duodenal ampulla); 1.5 represents the center of the pyloric stomach.
TABLE III. Mean weight $\left(\times 10^{-4} \mathrm{~g}\right)$ of 3 developmental stages of female Corynosoma cetaceum in 3 sites from 29 franciscana dolphins Pontoporia blainvillei: main stomach (MS), pyloric stomach (PS), and duodenal ampulla (DA).

\begin{tabular}{llccc}
\hline & & MS & PS & DA \\
\hline Stage 1 & $\mathrm{n}$ & 27 & 28 & 25 \\
& Mean \pm SD & $27.2 \pm 7.7$ & $33.8 \pm 15.0$ & $38.6 \pm 20.1$ \\
& Range & $12.3-41.6$ & $17.0-82.1$ & $18.6-100.0$ \\
Stage 2 & $\mathrm{n}$ & 23 & 29 & 25 \\
& Mean \pm SD & $47.6 \pm 14.4$ & $49.3 \pm 17.8$ & $51.6 \pm 18.8$ \\
& Range & $24.0-73.0$ & $27.0-100.3$ & $17.0-103.5$ \\
Stage 3 & $\mathrm{n}$ & 27 & 29 & 28 \\
& Mean \pm SD & $78.3 \pm 24.9$ & $72.9 \pm 16.3$ & $71.7 \pm 20.1$ \\
& Range & $33.5-144.0$ & $42.8-115.2$ & $28.1-107.5$ \\
\hline
\end{tabular}

MS females differed in biomass $(P<0.05)$ with respect to those of the PS and the DA. The mean biomass of gravid females covaried strongly and positively among the 3 chambers (Kendall test, $W=0.87,28 \mathrm{df}, P=0.009$ ). In each chamber, we found no significant correlation between mean biomass of gravid females and either total or chamber intensity (Spearman correlation tests, $r_{s}$ ranging from -0.17 to 0.18 ; minimum 1tailed nominal $P>0.18$ ).

Mean biomass of females selected for fecundity analysis did not differ among chambers (Quade test, $T_{(2,28)}=0.11 P>>$ $0.05)$. There was a weak positive relationship between biomass and fecundity $\left(r_{s}=0.37, \mathrm{n}=225, P<0.001\right)$. Values of mean fecundity $\left(\times 10^{3}\right)$ per chamber were $50.8 \pm 32.3(\mathrm{MS}), 48.2 \pm$ 25.3 (PS), and $44.3 \pm 25.1$ (DA). A Quade test indicated no significant fecundity differences among chambers $\left(T_{(2,28)}=\right.$ $0.10, P>0.05$ ). A strong positive covariation in fecundity was found among chambers $(W=0.91,14 \mathrm{df}, P<0.0001)$. We failed to detect any negative relationship between fecundity and either total or chamber intensity $\left(r_{s}\right.$ ranging from -0.340 to -0.025; minimum 1-tailed nominal $P>0.1$ ).

\section{DISCUSSION}

A preliminary concern in this study was whether observed habitat use would be affected by postmortem effects. These effects were considered as unimportant at the degree of resolution employed (among chambers) for several reasons. First, specimens of $C$. cetaceum did not exhibit signs of degeneration except for senescent worms in the rectum; this indicates that there was no substantial destruction of worms during the time elapsed between host death and necropsy. Second, most $C$. cetaceum specimens were found firmly attached to the wall of each chamber, such as observed in previous studies (Yamasaki et al., 1974; Brownell, 1975). This strongly suggests that worms likely died in the same chambers where they had lived. The RI, where worms were detached, was considered as an unsuitable habitat. This interpretation agrees with observations by Brownell (1975) and Andrade et al. (1997), who found C. cetaceum in the MS, PS, and DA, but not in the RI, of large samples of franciscanas. Third, assuming that $C$. cetaceum individuals could have moved in response to postmortem cues, the gross resolution employed to analyze habitat selection should minimize the importance of worm movements among chambers. However, if chambers are relatively isolated, senescent worms 
coming from anterior chambers might remain for long periods in posterior chambers. This problem seems negligible for 2 reasons. First, it has already been noted that most worms were attached. Second, detached worms should be quickly eliminated because evacuation is fast in cetaceans (Smith, 1972). In fact, the low number of individuals found in the RI (mean, 6; median, 1) possibly represents the sum of all senescent worms coming from the MS, PS, and DA.

The sex ratio in acanthocephalans appears to be genetically determined with a zygotic ratio of $1: 1$ and remains so until after copulation; however, adult males generally have a shorter life span and, therefore, the sex ratio becomes biased against males in late infections (Parshad and Crompton, 1981; Crompton, 1985; Kennedy, 1993). Experimental and field observations of several species of Corynosoma are consistent with this general pattern (Helle and Valtonen, 1980, 1981; Valtonen and Helle, 1982). The sex ratio of $C$. cetaceum was also biased against males, although sex ratio was heterogeneous among chambers. In the RI, the sex ratio was biased toward males, indicating that senescent males accumulate at a higher proportion there, as would be expected if males have a shorter life span. In the MS, the sex ratio was biased against males, but it was notably closer to $1: 1$ compared to values in the PS and the DA. This pattern suggests that newly recruited cystacanths mainly excyst and activate in the MS. This interpretation is also supported by the observation that stage 1 females were in a comparatively higher proportion in the MS and had a more anterior location than those of stages 2 and 3 (Table II). Also, stage 1 females, but not those of stages 2 and 3, were of smaller size in the MS than in the PS and the DA. This observation strongly suggests that many stage 1 females from the MS were recruited recently. In fact, many stage 1 females were very small and in early sexual development. The release of cystacanths from prey tissues in the MS seems a logical outcome of the digestive physiology of franciscanas; prey are first digested in the MS (Yamasaki et al., 1974) and must be reduced to semifluid chyme at this stage of digestion (Gaskin [1978] and references therein).

Once cystacanths are released in the MS, they seem to be able to establish and reproduce in the MS, PS, and DA. Significant differences were not observed in mean biomass or fecundity of gravid females among chambers. Also, the maturity status of females was nearly identical between the PS and DA; the higher proportion of stage 1 females in the MS is probably related to a higher occurrence of newly recruited individuals to this site, as discussed previously. In addition, mean biomass and fecundity of gravid females covaried strongly, and positively, among chambers within hosts. This does not seem to be related to common intensity-related effects. Regardless of alternative causes to account for such covariation, all chambers appear to be affected in a similar manner. Collectively, the sum of these results is interpreted as evidence that there are no major differences between the 3 chambers regarding their suitability for reproduction by $C$. cetaceum. However, this does not imply that all chambers are exactly equivalent as reproductive habitats. Reproductive success of acanthocephalans depends on a number of factors, such as level of nutrients, immune responses, or intensity-dependent effects that could interact in a complex way (Crompton, 1985; Kennedy, 1993). In natural infections, it is extremely difficult to distinguish subtle differences among habitats concerning these or other factors (Bates and Kennedy, 1991).
An obvious question becomes why the MS, which is the largest chamber, contained the smallest number of reproductive females. In situ observations revealed that attached individuals of C. cetaceum occurred throughout the MS and the DA; however, in the MS, worms were found mainly on the bottom of the chamber, near the opening of the connecting channel (see Yamasaki et al. [1974] for a similar observation). Therefore, the effective attachment area in the MS might be smaller than that of the PS and perhaps comparable to that of the DA. If worms absorb nutrients provided by host diet, a preferential attachment on the aboral part of the MS makes sense; the chyme that results from the first chemical digestion in the MS is concentrated in the aboral region, prior to being propelled through the connecting channel (Harrison et al., 1970; Olsen et al., 1994). The aboral part of the MS might also represent a sheltered region for worm attachment, because mechanical breakdown of entire fish, cephalopods, and crustaceans takes place in this stomach. To clarify this question further, it would be interesting to study the distribution of C. cetaceum in other species of cetaceans (Torres et al., 1992; Corcuera et al., 1995). In other cetaceans, mechanical and, to some extent, chemical digestion occur in the forestomach (Gaskin, 1978), a chamber lacking in franciscanas. Neither the PS nor the DA are thought to contribute to chemical digestion, their role being to neutralize the acidity of chyme (Gaskin [1978] and references therein). Chemical breakdown continues in the duodenum proper, a region that also receives secretions from the liver and pancreas (Yamasaki et al., 1975). Therefore, the digestive state of food and the possible presence of available nutrients for $C$. cetaceum would not be altered substantially in the PS and the DA.

The median worm and the posterior worm, but not the anterior worm, of gravid female $C$. cetaceum were more posteriad at increasing numbers of gravid females. However, the pattern was only apparent at low intensities, and both the median worm and the posterior worm soon reached roughly constant values (the center of the PS and the end of the DA, respectively). This pattern is consistent with occupation of chambers according to available space, thus supporting the notion that individual $C$. cetaceum do not display a strong chamber preference. At low intensities, gravid females would establish mainly in the MS and the PS. At increasing numbers, worms would tend to establish mainly in the PS because it is the chamber providing the largest space. A measure of the effective space provided by each chamber would permit an estimation of density, which would allow this hypothesis to be tested.

In conclusion, the evidence suggests that $C$. cetaceum mainly excysts and activates in the MS; it then establishes and reproduces in the aboral region of MS, the PS, and the DA. Our results also suggest that the 3 chambers do not differ much in suitability as reproductive habitats for $C$. cetaceum. Based on the available data, the stomach should, therefore, be considered the primary habitat for $C$. cetaceum in the franciscana. The use of this exceptional habitat is puzzling. As far as it is known, the upper gastrointestinal tract of cetaceans is not substantially different from that of other mammals regarding fine histology or physiology (Gaskin, 1978; Berta and Sumich, 1999). So, what do individuals of $C$. cetaceum absorb in the stomach? If it is assumed that these individuals rely on digested food, they would seem to require only nutrients derived from digestion in the MS. The stomach is also a harsh habitat because of physical 
disturbance. In fact, C. cetaceum possesses many adaptations to counteract drag (Aznar, Bush, Fernández, and Raga, 1999). More surprisingly, C. cetaceum is absent from sites where fine chemical breakdown of food and nutrient absorption occurs, i.e., the intestine proper, in contrast with other species of Corynosoma (see references in Golvan [1994]). What selective forces could have driven $C$. cetaceum into the stomach? Microhabitats of helminths are defined by long histories of adaptation, and therefore, initial mechanisms leading to selection of particular habitats may be masked by subsequent adaptations to those habitats (Richardson and Nickol [2000] and references therein). This means that the above questions will never be answered satisfactorily, but they will certainly stimulate thought about what type of constraints limit habitat selection by acanthocephalans.

\section{ACKNOWLEDGMENTS}

We are grateful to J. Corcuera and F. Monzón for collecting parasites. Technical assistance by V. Herreras, A. Córdoba, and L. Klein is also appreciated. We also thank 2 anonymous referees who improved the paper. This work is supported by projects DGES PB96-0801 (MEC) and 1FD97-1147 (CICYT) of Spain and A-8090 (NSERC) of Canada. F.J.A. benefits from a postdoctoral contract from the MEC of Spain.

\section{LITERATURE CITED}

Andrade, A., M. C. Pinedo, And J. Pereira. 1997. Gastrointestinal helminths of the franciscana, Pontoporia blainvillei, in southern Brazil. Reports of the International Whaling Commission 47: 669-673.

Aznar, F. J., J. A. Balbuena, and J. A. Raga. 1994. Helminth communities of Pontoporia blainvillei (Cetacea: Pontoporiidae) in Argentinean waters. Canadian Journal of Zoology 72: 702-706.

- A. O. Bush, AND J. A. Raga. 1999. Polymorphus arctocephali Smales, 1986 a synonym of Corynosoma cetaceum Johnston \& Best, 1942 (Acanthocephala: Polymorphidae). Systematic Parasitology 44: 59-70.

-, , M. FernándeZ, AND J. A. Raga. 1999. Constructional morphology and mode of attachment of the trunk of Corynosoma cetaceum (Acanthocephala: Polymorphidae). Journal of Morphology 241: 237-249.

Bates, R. M., AND C. R. Kennedy. 1990. Interactions between the acanthocephalans Pomporhynchus laevis and Acanthocephalus anguillae in rainbow trout: Testing an exclusion hypothesis. Parasitology 100: $435-444$.

$\longrightarrow$, AND — 1991. Site availability and density-dependent constraints on the acanthocephalan Pomphorhynchus laevis in rainbow trout, Oncorhynchus mykiss (Walbaum). Parasitology 102: 405-410.

Berta, A., And J. L. Sumich. 1999. Marine mammals. Evolutionary biology. Academic Press, San Diego, California, 494 p.

Brownell, R. L., JR. 1975. Progress report on the biology of the franciscana dolphin, Pontoporia blainvillei, in Uruguayan waters. Journal of the Fisheries Research Board of Canada 32: 1073-1078.

Bush, A. O., AND J. C. Holmes. 1986. Intestinal helminths of lesser scaup ducks: An interactive community. Canadian Journal of Zoology 64: 142-152.

—, K. D. Lafferty, J. M. Lotz, and A. W. ShostaK. 1997. Parasitology meets ecology on its own terms: Margolis et al. revisited. Journal of Parasitology 83: 575-583.

Conover, W. J. 1980. Practical nonparametric statistics, 2nd ed. John Wiley and Sons, Inc., New York, New York, 493 p.

Corcuera, J., F. Monzón, A. Aguilar, A. Borrell, and J. A. Raga. 1995. Life history data, organochlorine pollutants and parasites from eight Burmeisteir's porpoises, Phocoena spinipinnis, caught in northern Argentine waters. Reports of the International Whaling Commission 16: 365-372.

Crompton, D. W. T. 1973. The sites occupied by some parasitic helminths in the alimentary tract of vertebrates. Biological Reviews 48: $27-83$.

- 1985. Reproduction. In Biology of the Acanthocephala, D. W.
T. Crompton and B. B. Nickol (eds.). Cambridge University Press, Cambridge, U.K., p. 213-271.

EFrON, B. 1982. The jackknife, the bootstrap and other resamplings plans. SIAM (Society for Industrial and Applied Mathematics) Monograph 38: 1-92.

Figueroa, L., AND S. PUGa. 1990. Corynosoma cetaceum Johnston y Best, 1942 (Acanthocephala) en delfín chileno, Cephalorhynchus eutropia Gray, 1846 (Cetacea: Delphinidae). Boletín Chileno de Parasitología 45: 93-95.

Garson, G. I., AND E. B. Moser. 1995. Aggregation and the Pearson chi-square statistic for homogeneous proportions and distributions in ecology. Ecology 76: 2258-2269.

GASKIN, D. E. 1978. Form and function in the digestive tract and associated organs in Cetacea, with consideration of metabolic rates and specific energy budgets. Oceanography and Marine Biology Annual Reviews 16: 313-345.

Golvan, Y. J. 1994. Nomenclature of the Acanthocephala. Research and Reviews in Parasitology 54: 135-205.

Harrison, R. J., F. R. Johnson, And B. A. Young. 1970. The oesophagus and stomach of dolphins (Tursiops, Delphinus, Stenella). Journal of Zoology (London) 160: 377-390.

Helle, E., AND E. T. VAltonen. 1980. On the ocurrence of Corynosoma spp. (Acanthocephala) in ringed seals (Pusa hispida) in the Bothnian Bay, Finland. Canadian Journal of Zoology 58: 298-303.

— AND —. 1981. Comparison between spring and autumn infections by Corynosoma (Acanthocephala) in the ringed seal Pusa hispida in the Bothnian Bay of the Baltic Sea. Parasitology 82: 287-296.

Kagei, N., T. Tobayama, And Y. NAgasaki. 1976. On the helminthum of franciscana, Pontoporia blainvillei. Scientific Reports of the Whale Research Institute 28: 161-166.

KenNeDY, C. R. 1985. Site segregation by species of Acanthocephala in fish, with special reference to eels, Anguilla anguilla. Parasitology 90: $375-390$.

- 1993. Acanthocephala. In Reproductive biology of invertebrates, Vol. 6, pt. A, A. D. Adiyodi and K. G. Adiyodi (eds.) Oxford and IBH, New Delhi, India, p. 279-295.

Olsen, M. A., E. S. Nordoy, A. S. Blix, ANd S. D. Mathiesen. 1994. Functional anatomy of the gastrointestinal system of Northeastern Atlantic minke whales (Balaenoptera acutorrostrata). Journal of Zoology (London) 234: 55-74.

Parshad, V. R., AND D. W. T. Crompton. 1981. Aspects of acanthocephalan reproduction. Advances in Parasitology 19: 73-138.

PetrochenKo, V. I. 1956. Acanthocephala of domestic and wild animals, Vol. 1. Izdatel'stvo Akademii Nauk SSSR, Moscow. English translation by Israel Program for Scientific Translations Ltd., 1971, 435 p.

Rice, W. R. 1989. Analyzing tables of statistical tests. Evolution 43: 223-225.

RichARDSON, D. J., AND B. B. NICKOL. 2000. Experimental investigation of physiological factors that may influence microhabitat specificity exhibited by Leptorhynchoides thecatus (Acanthocephala) in green sunfish (Lepomis cyanellus). Journal of Parasitology 86: 685-690.

Sмith, G. J. D. 1972. The stomach of the harbour porpoise Phocoena phocoena (L.). Canadian Journal of Zoology 50: 1611-1616.

Starling, J. A. 1985. Feeding, nutrition and metabolism. In Biology of the Acanthocephala, D. W. T. Crompton and B. B. Nickol (eds.). Cambridge University Press, Cambridge, U.K., p. 125-212.

Torres, P., J. A. Oporto, L. M. BRIEVA, AND L. Escare. 1992. Gastrointestinal helminths of the cetaceans Phocoena spinipinnis (Burmeister, 1865) and Cephalorhynchus eutropia (Gray, 1846) from the southern coast of Chile. Journal of Wildlife Diseases 28: 313-315.

Valtonen, E. T., and E. Helle. 1982. Experimental infection of laboratory rats with Corynosoma semerme (Acanthocephala). Parasitology 85: 9-19.

Yamasaki, F., K. Takahasi, and T. KamiYa. 1974. Digestive tract of La PLata dolphin, Pontoporia blainvillei. I. Oesophagus and stomach. Okajimas Folia Anatomica Japonica 51: 29-52.

- - AND 1975. Digestive tract of La Plata dolphin, Pontoporia blainvillei. II. Small and large intestines. Okajimas Folia Anatomica Japonica 52: 1-26.

ZDZITOWIECKI, K. 1984. Redescription of Corynosoma hamanni (Linstow, 1982) and description of C. pseudohamanni sp. n. (Acanthocephala) from the environs of the South Shetlands (Antarctic). Acta Parasitologica Polonica 24: 379-393. 